\title{
Students embracing change towards more powerful learning environments in vocational education
}

Citation for published version (APA):

Plackle, I., Konings, K. D., Jacquet, W., Libotton, A., van Merrienboer, J. J. G., \& Engels, N. (2018). Students embracing change towards more powerful learning environments in vocational education. Educational Studies, 44(1), 26-44. https://doi.org/10.1080/03055698.2017.1331840

Document status and date:

Published: 01/01/2018

DOI:

10.1080/03055698.2017.1331840

Document Version:

Publisher's PDF, also known as Version of record

Document license:

Taverne

Please check the document version of this publication:

- A submitted manuscript is the version of the article upon submission and before peer-review. There can be important differences between the submitted version and the official published version of record.

People interested in the research are advised to contact the author for the final version of the publication, or visit the DOI to the publisher's website.

- The final author version and the galley proof are versions of the publication after peer review.

- The final published version features the final layout of the paper including the volume, issue and page numbers.

Link to publication

\footnotetext{
General rights rights.

- You may freely distribute the URL identifying the publication in the public portal. please follow below link for the End User Agreement:

www.umlib.nl/taverne-license

Take down policy

If you believe that this document breaches copyright please contact us at:

repository@maastrichtuniversity.nl

providing details and we will investigate your claim.
}

Copyright and moral rights for the publications made accessible in the public portal are retained by the authors and/or other copyright owners and it is a condition of accessing publications that users recognise and abide by the legal requirements associated with these

- Users may download and print one copy of any publication from the public portal for the purpose of private study or research.

- You may not further distribute the material or use it for any profit-making activity or commercial gain

If the publication is distributed under the terms of Article $25 \mathrm{fa}$ of the Dutch Copyright Act, indicated by the "Taverne" license above, 


\section{Educational Studies}

\section{Students embracing change towards more powerful learning environments in vocational education}

Inge Placklé, Karen D. Könings, Wolfgang Jacquet, Arno Libotton, Jeroen J. G. van Merriënboer \& Nadine Engels

To cite this article: Inge Placklé, Karen D. Könings, Wolfgang Jacquet, Arno Libotton, Jeroen J. G. van Merriënboer \& Nadine Engels (2018) Students embracing change towards more powerful learning environments in vocational education, Educational Studies, 44:1, 26-44, DOI: 10.1080/03055698.2017.1331840

To link to this article: https://doi.org/10.1080/03055698.2017.1331840

曲 Published online: 05 Jun 2017.

Submit your article to this journal

Llll Article views: 617

Q View related articles $\sqsubset$

View Crossmark data $₫$ 


\title{
Students embracing change towards more powerful learning environments in vocational education
}

\author{
Inge Plackléa,b,d, Karen D. Könings s', Wolfgang Jacquet ${ }^{a}$, Arno Libotton ${ }^{a, b}$, Jeroen J. G. \\ van Merriënboer ${ }^{c}$ and Nadine Engels ${ }^{\mathrm{a}, \mathrm{b}}$
}

${ }^{a}$ Educational Sciences and Teacher Education, EDWE, Vrije Universiteit Brussel, Brussels, Belgium; ${ }^{\mathrm{b} T e a c h e r}$ Education, IDLO, Vrije Universiteit Brussel, Brussels, Belgium; 'Department of Educational Development \& Research, School of Health Professions Education, Maastricht University, Maastricht, The Netherlands; dEducation, PXL University College, Hasselt, Belgium

\begin{abstract}
Students' educational engagement is both an important predictor of study success and a key preventive factor for dropout. Vocational tracks in secondary education show high dropout rates. There is strong evidence that the solution to educational disengagement lies in student-centred, powerful learning environments (PLEs). This study investigates characteristics of PLEs from the perspective of students in vocational secondary education. Students' perspectives on a learning environment are crucial for their satisfaction and learning engagement. Therefore, we investigated whether the perceived learning environment meets the requirements of PLEs, and to what extent it meets students' preferences. Additionally, it was investigated whether students who perceive their learning environment as more powerful, are also more engaged for school. Survey data of 532 students showed that student perceptions of their current learning environment were largely discrepant from the characteristics of PLEs. Students strongly asked for more challenging learning pathways, in combination with adaptive learning support. Students who perceived the characteristics of PLEs as being present, reported higher satisfaction and stronger engagement than students who perceived their education to be a less powerful environment. There is a need to redesign curricula in vocational education in such a way that these more intensely implement characteristics of PLEs.
\end{abstract}

\section{ARTICLE HISTORY}

Received 12 November 2016 Accepted 5 April 2017

\section{KEYWORDS}

Secondary vocational education; powerful learning environment; student perception; student engagement

Every student has the right to succeed in education. This is a challenge, especially for vocational students in Europe, as shown by the current high dropout rates (Lamb et al. 2011). In Flanders more than one fifth of students in vocational education leave school without a qualification (Van Landeghem and Van Damme 2011). Students' educational engagement is both an important predictor of study success and a key preventive factor. Engagement has been shown to predict student achievement and school dropout (Finn, Pannozzo, and Voelkl 1995; Klem and Connell 2004). While it is affected by social background, it is also strongly influenced by school-related factors, including pedagogy and curriculum (Fullarton 2002; Willms 2003; Murray et al. 2004; Walsh and Black 2009). There is strong evidence that 
the solution to educational disengagement lies in student-centred learning environments and a strong focus on the quality of teaching and learning (Macleod, Sharp, Skipp, and Bernardinelli 2015).

Teachers are designers of learning environments in order to promote optimal learning by their students; They try to develop environments which actively strengthen students' capacities to learn (Hargreaves 2004). Teachers design learning environments for students, seldomly with them, which makes it more difficult to involve student perspectives in the development of the learning environment. Students are major partners in education and their satisfaction with the learning environment does influence the quality of learning (Könings, Brand-Gruwel, and Van Merriënboer 2010). How students experience their learning environment is crucial because their perspectives determine their engagement (Könings, Seidel, and van Merriënboer 2014). Discrepancies between student preferences and perceived opportunities in the learning environment could be seen as an expression of student dissatisfaction with their learning experiences, leading to a decrease in engagement (Könings et al. 2011b).

Fredricks, Blumenfeld, and Paris (2004) state that student engagement results from active participation in academic and school-related activities and commitment to educational goals and learning. Student engagement drives learning and can be achieved for all learners, but it requires energy and effort. It is a multidimensional construct that consists of behavioural, emotional and cognitive dimensions (McCormick, Kinzie, and Gonyea 2013). Behavioural engagement refers to involvement in learning tasks (students' effort, attention and persistence) during the initiation and execution of learning activities (Skinner and Belmont 1993; Skinner et al. 2008) and positive conduct (i.e. following rules, absence of disruptive behaviours, participation in school-related activities; Finn, Pannozzo, and Voelkl 1995). Emotional engagement refers to student's general affect and emotions in relation to education (Anderman and Freeman 2004). Cognitive engagement is seen as student's "autonomous motivation" (acting out of choice and pleasure) vs. "controlled motivation" (behaving to avoid punishment, or trying to avoid feelings of guilt). Autonomous motivation is seen as the most effective type of motivation for learning (Deci and Ryan 2002). Internalisation of students' motivation towards autonomous motivation is associated with increased satisfaction with education. Teachers foster autonomous motivation when they create an environment that facilitates the fulfilment of students' needs.

Shernoff (2014) suggested that the level of engagement is correlated with a set of principles that together define the learning environment. Opdenakker and Van Damme (2009) found that the more teachers created student-centred environments, the higher the engagement of their students was. In addition, Alfassi (2004) found that for students at risk the level of engagement increases in a student-centred environment, because it stands for a strengthening of the focus on teaching and learning, starting from students' strengths and talents. Although most research conceptualises student engagement as a relatively stable property of individual learners, it is also argued that characteristics of the learning environment, and how these characteristics are perceived by the student, have an even greater impact on student engagement than individual characteristics (Shernoff 2010). That is, the learning environment seems a very salient variable influencing engagement.

In this study we will investigate the role of the design characteristics of a learning environment, within the case of an integrated curriculum design for general subjects in 
vocational secondary education, play for improving student satisfaction and student engagement.

Student-centred learning environments - emphasising the integration of domain-specific knowledge and skills with cognitive and emotional self-regulation skills, which together help students tackle everyday problems and situations - are usually based on a constructivist epistemology and grouped together as so-called Powerful Learning Environments (PLEs; De Corte 1990). Characteristics of PLEs in Secondary Vocational Education have been determined as well (Placklé et al. 2013). Based on a literature study and endorsed by PGS teacher educators, PGS teachers and vocational students, Figure 1 (Placklé et al. 2014) depicts these characteristics in the so-called PoLEVE-model - Powerful Learning Environments in Vocational Education. The PoLEVE model visualises interdependence of the various characteristics that together, and in interaction with each other, aim to maximally improve learning - including engagement on the part of every student. The student is situated in the middle, as the centre of teaching and learning. The principles are: (1) challenging and authentic learning environments, (2) opportunities for the development of key competencies, (3) adaptive learning

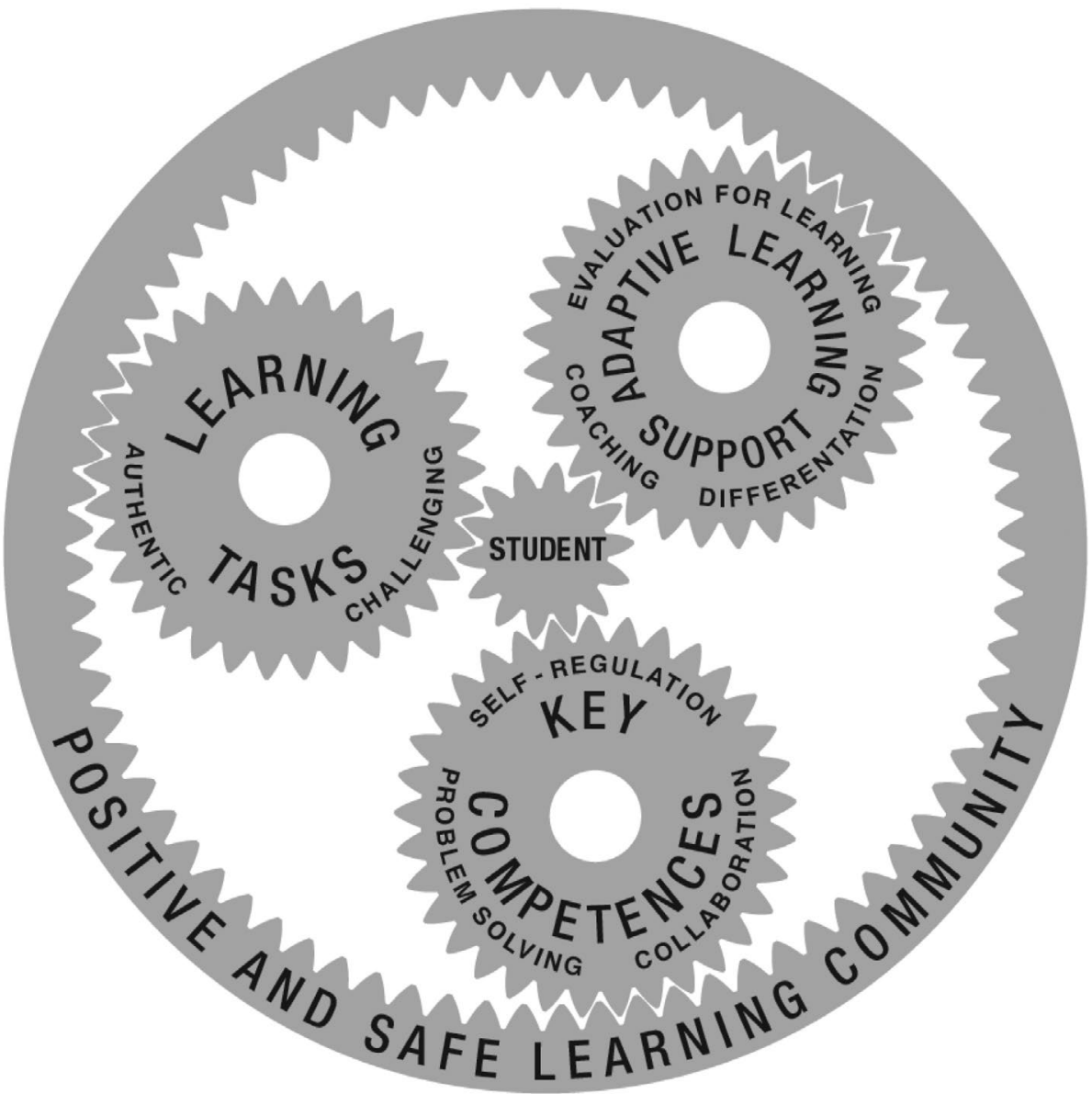

Figure 1. Model for Powerful Learning Environments in Vocational Education (PoLEVE-model) (Placklé et al. 2013; Placklé et al. 2014). 
support that teachers aim to offer and (4) a positive and safe learning community in which the former three principles are embedded.

For the first principle regarding the learning environment, it is stressed that attractive education has to be challenging and meaningful (De Bruijn and Leeman 2011). Challenging learning pathways connect to students'lives (Rumberger 2012) and present authentic tasks, requiring challenging thought and allowing time for exploration (Smyth and Fasoli 2007). These tasks are often assignments or problems taken from daily life and/or vocational practice, though they may need to be re-designed to be applicable in education. The complexity of the real world should be reflected as an essential feature of the learning tasks (Vansteenkiste et al. 2012).

For the second principle regarding key competencies, self-regulated learning, collaborative learning and problem-solving are characteristics of effective learning processes at the heart of PLEs (De Corte 2003; Könings, Brand-Gruwel, and Merriënboer 2005). Self-regulated learning implies that students take control of their own learning, including - within the framework of their curriculum - the stipulation of their own personal learning goals, the choice of appropriate learning activities to work on these goals and reflection on their learning (Boekaerts and Niemivirta 2000; Cleary and Zimmerman 2004; Kicken et al. 2009). Working in small groups can enhance problem-solving performance and learning (Sears and Reagin 2013). Nelson (1999) explicitly stipulated the importance of "collaborative problem solving". While working in small groups and within reciprocal relationships, each student has opportunities to participate and learn from his or her peers (Cohen 1994; Johnson and Johnson 2009).

The third principle is adaptive learning support. Vocational Education is characterised by a very heterogeneous student population, which we also experience in Flanders. Students differ in cultural background, language, interests, values, socio-economic status and academic readiness. To meet the needs of these diverse students, the curriculum must be adapted to the background, strengths and interests of the students (Tomlinson and Germundson 2007; De Bruijn and Leeman 2011). This implies that there is a need for adaptive teaching that is supportive and varied, while meeting the preferences and needs of individual students, and at the same time offering learning tasks that are challenging and attractive both on an individual level and on a group level. Strategies of adapting education to students' needs - differentiation - are an integral part of an educational approach that tries to improve the learning of all students (Tomlinson and Javius 2012). This also implies evaluation for learning throughout the learning process, contributing to the improvement of the learning processes in a continuous way (Tomlinson 1999; Brown 2004; Harris and Brown 2013; Brown and Harris 2014). The integral part of adaptive learning and teaching support is that teachers provide coaching that offers appropriate structure and trust, and that stimulates students to self-regulate their learning (Kirschner, Sweller, and Clark 2006; Jang, Reeve, and Deci 2010; Vansteenkiste et al. 2012; Van Merriënboer and Kirschner 2013). Winters (2012) highlighted that the most suitable guidance conversation must be dialogical, which implies that it stimulates and supports students to reflect on their own performance and learning. Reflective dialogue with peers is related to student engagement and the development of reflective consciousness (Richards and Richards 2013).

The fourth characteristic visualises a positive and safe learning community as a prerequisite for learning (Rubin 2006; Hattie 2009). An optimal classroom climate is characterised by warm and supportive teacher-student relationships and peer relationships, appropriate 
expressions of emotion and respectful communication, a strong interest in and focus on learning tasks and building on students' strengths, abilities and needs, within a culture were individual differences are negotiable and common (La Paro and Pianta 2003; Jennings and Greenberg 2009). Such a culture is not a coincidental occurrence, but is intentionally built up and embedded in the structure of teaching and learning (Shernoff 2014).

In this study we investigate the impact of students' perceptions regarding characteristics of PLEs, as described in the PoLEVE model, on students' satisfaction with their learning environment and their engagement. We expect that students who perceive their learning environment as being more in line with the PoLEVE characteristics will be more satisfied with their education and also be more engaged for learning than students who do not recognise these characteristics in their learning environment. This will be investigated in the context of a newly developed multidisciplinary and integrated course, Project General Subjects (PGS) in Vocational Education. In PGS, functional maths, language and information processing skills are integrated in a course that has a curricular emphasis on life challenges, social problems and/or vocational problems, and in which social resilience and social responsibility are developed at the same time. It is aimed to be a PLE.

Five research questions will be answered:

RQ1 - Do students in vocational education perceive their learning environment as a PLE, as operationalised in the PoLEVE model?

RQ2 - Are student preferences regarding their learning environment in line with the characteristics of a PLE?

RQ3 - Do student perceptions differ from their preferences? Do they prefer the characteristics of PLEs to be implemented more or less strongly?

RQ4 - Is there a relation between student perceptions of their current learning environment and their level of satisfaction with it?

RQ5 - Are students who perceive their current learning environment as more powerful also more emotionally engaged and more autonomously engaged for going to school?

\section{Method}

\section{Participants}

Students in the 5th year $(n=208), 6$ th year $(n=166)$ and 7th year $(n=158)$ of secondary vocational education filled out questionnaires about their perceptions of their current learning environment $(N=532)$. Students (295 girls and 237 boys) were 16 to 24 years old $(M=17.34 ; S D=1.24)$. We used a convenience sample of nine schools in Flanders (Belgium). The schools varied in the extent to which they were involved in innovative educational projects. The schools varied in size (from 197 to 940 students) and in location (from provincial capitals to rural municipalities). Both state schools and Catholic schools were involved. Three schools offered only vocational and technical education; six schools also offered general education. One school did not participate because of an overly heavy workload caused by internal factors. Student demographics varied between schools, although all showed a high percentage of students with low socio-economic status (SES, $M_{\text {low SES }}=66 \%$, with a range between 52 and 76\%). SES indicators were: Home language other than Dutch, receiving school financing and a mother without secondary education. 


\section{Materials}

The "Inventory of Perceived and Preferred characteristics of Powerful Learning Environments" (IPoLEVE; Placklé et al. 2013; Placklé et al. 2014) was used for data collection. Additionally, an instrument on "learning engagement" was administered.

The IPoLEVE was developed to measure students' perspectives on PLEs in vocational education (Placklé et al. 2013; Placklé et al. 2014). It measures eight dimensions of the PoLEVE model in vocational education, as shown in Table 1: (1) authentic \& challenging content, (2) self-regulated learning, (3) collaborative problem-solving, (4) assessment for learning, (5) differentiation, (6) coaching with the two subscales structure and trust, (7) reflective dialogue with teachers and (8) reflective dialogue with peers.

The IPoLEVE was originally based on existing instruments and qualitative research data (Placklé et al. 2013; Placklé et al. 2014). It contains 53 items: 24 items originate from the Inventory of Perceived Study Environment Extended (IPSEE; Könings, Brand-Gruwel, and van Merriënboer 2011a); 8 items originate from the Teacher As Social Context Questionnaire (TSCQ; Belmont et al. 1988); 6 items originate from the Students' conceptions of assessment inventory (VaSCoA-Vl; Brown 2008); 3 items originate from the observation instrument of PLE in vocational education (De Bruijn, Leeman, and Overmaat 2006) and 12 newly developed items were constructed in order to measure the characteristics of PLEs referring to adaptive learning support (i.e. differentiation and reflective dialogue).

For every item, students rated their perception ("This happens") as well as their preference ("I would like this to happen") on a 5-point Likert scale ranging from "always" to "almost never or never" except for the scale reflective dialogue, where a 4-point scale (from "often" to "almost never or never") was used, because the category "always" was not applicable here (e.g.:'I talk about what I would like to do in my future'). Reliability analyses were performed on each of the scales. The internal consistencies of the scales, which were generally high, and sample items can be found in Table 1. In total, 7 of 16 Cronbach's alpha coefficients (for each of the 8 scales, separately for perceptions and preferences) were above .90; 7 coefficients were between .80 and .90 and 2 coefficients were .79 .

Emotional engagement, defined as students' general affect and emotions towards education by Anderman and Freeman (2004), was measured with one overall item with a 4-point scale ranging from 1 ("I go to school against my will") to 4 ("I like to go to school very much").

Cognitive engagement was measured as students' autonomous motivation (acting out of choice and pleasure) vs. controlled motivation (behaving to avoid punishment, or trying to avoid feelings of guilt). Autonomous motivation is seen as the most effective motivation for learning (Deci and Ryan 2002). It was measured with one item in which students were asked to rank 5 alternative completions of the sentence "I put effort into PGS lessons because ..." from most important to least important. The alternatives represent autonomous motivation vs. controlled motivation. The most important alternatives got the highest weights, and vice versa. Alternatives referring to controlled motivation were reverse (negative) scored. A positive vs. negative total score defined whether a student is more autonomous vs. controlled motivated. This resulted in a binary variable (score $=1$ or 0 ). Table 2 shows the items measuring students' emotional and cognitive engagement.

\section{Procedure}

The administration of the survey was scheduled in the schools' timetables and therefore the degree of participation was $100 \%$ of the students present on the day the survey was 


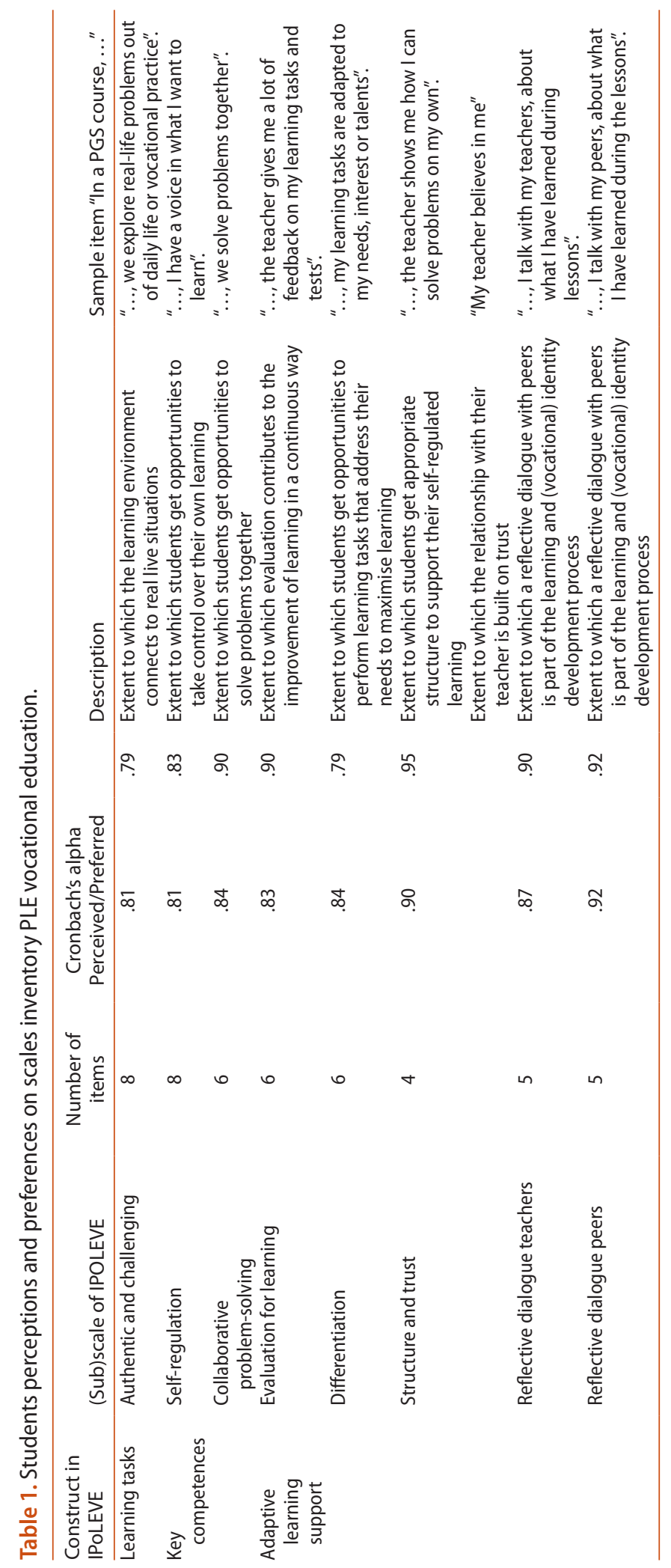


Table 2. Measures emotional and cognitive engagement of students.

\begin{tabular}{|c|c|c|}
\hline Type of engagement & Description & Answering categories \\
\hline Emotional Engagement & $\begin{array}{l}\text { Students' overall attitude } \\
\text { towards school }\end{array}$ & $\begin{array}{l}\text { "I like to go to school very much" (like) } \\
\text { "I like to go" (like) } \\
\text { "I don"t like to go' (don't like) } \\
\text { "I go against my will" (don't like) }\end{array}$ \\
\hline Cognitive Engagement & $\begin{array}{l}\text { Autonomous (aut) vs. Controlled } \\
\text { (con) Motivation (rank item) }\end{array}$ & $\begin{array}{l}\text { "I put effort in the lessons because ..." } \\
\text { "... I I find the lessons fascinating and challenging" (aut) } \\
\text { "... youngsters of my age have to do this" (con) } \\
\text { "... I would like to prepare myself for my later life" (aut) } \\
\text { "... I would like to get my certification/grade" (aut) } \\
\text { "... I want to avoid negative consequences" (con) }\end{array}$ \\
\hline
\end{tabular}

administered. Schools had an option for a survey on paper $(n=203)$ or online $(n=339)$. For the paper version, students received oral instructions from the researcher. For the online version, students received an instruction card that was explained by the researcher at the beginning of the session. All students had 30 min to fill out the survey.

\section{Data analyses}

The first step was to clean the data-set and deal with missing data. Since the online version did not allow students to skip items, missing data only occurred in the written questionnaire (between 7.4 and $14.5 \%$ in the written version). In total, a limited amount of data was missing ranging from $2.8 \%$ missing values for the scale measuring self-regulated learning, up to $5.6 \%$ for the differentiation scale. To reduce the possible biasing impact that these missing data can have on the results, multiple imputation (MI) techniques were used (Peugh and Enders 2004).

For uniform interpretation of all scale scores, the scores of the IPoLEVE were recoded to proportions from 0 to 1. Means $(M)$ and standard errors (SEM) across the sets were computed to address what student perceptions (RQ1) and preferences (RQ2) were towards their learning environments. To test whether perceptions or preferences were significantly different from the neutral score of .50 , sample $t$-tests were performed separately on ten repeated imputation data-sets. We computed SEM instead of SD because repeated imputations allows to give good estimates of the standard errors, and because there are no pooled SDs (Little and Rubin 2002). The normality approximation is valid due to the large sample size. The difference scores between perceptions and preferences (RQ3) per participant indicate a positive dissatisfaction (i.e. students would prefer a higher visibility of the characteristics) or a negative dissatisfaction (i.e. preferring a lower visibility of the characteristic in the learning environment). Cohen (1994) has defined effect sizes of .2 as small, .5 as medium and .8 as large.

To investigate whether and how perceptions regarding the characteristics of PLE are related to student satisfaction (RQ4) and engagement (RQ5), we clustered the students in groups who perceived their learning environment - taking into account all IPOLEVE scales - as low, medium and high powerful and applied a K-means clustering algorithm (Hartigan and Wong 1979). The cluster analysis technique grouped students in such a way that the degree of association with respect to the perceived characteristics of the IPoLEVE between two students is maximal if they belong to the same group and minimal otherwise.

Subsequently, associations were explored between each cluster (low, middle and high perceived PLE) and both student satisfaction and student engagement. A Chi-square test 
was used to test for statistical significance of the associations and $p$-values $<.05$ were considered significant.

\section{Results}

Table 3 presents the results on mean perception scores and preference scores, as well as the differences between the scores and .50 (indicating a neutral answer) on the different scales of the IPoLEVE.

$R Q 1$ - Do students in vocational education perceive their current learning environment powerful as operationalised in the IPoLEVE? Student perception scores on their current learning environment regarding "authentic and challenging learning tasks" $(M=.59$, $\mathrm{SEM}=.04, d=.09)$ were significantly higher than the neutral score of $.50(p<.05)$. Perception scores on "self-regulated learning" $(M=.61, \mathrm{SEM}=.04, d=.11)$ and "collaborative problem solving" ( $M=.62, \mathrm{SEM}=.03, d=.16)$ were significant higher than the neutral score, but only with a small effect size. "Assessment for learning" $(M=.54$, SEM $=.04, d=.04)$, "differentiation" $(M=.44, \mathrm{SEM}=.04, d=.07)$ and "structure and trust" $(M=.59, \mathrm{SEM}=.06, d=.07)$ did not differ significantly from the neutral score. Perception scores for "reflective dialogue with teachers" $(M=.35, \mathrm{SEM}=.04, d=.18)$ and "reflective dialogue with peers" $(M=.31, \mathrm{SEM}=.03$, $d=.31)$ were significantly lower than the neutral score with small effect sizes.

Thus, student perception scores indicated that particularly authentic and challenging learning tasks and self-regulated learning and collaborative problem-solving were perceived as being present in the current learning environment.

RQ2 - What did students' preferred learning environment look like? As can be seen in the right part of Table 3, student preference scores were well above the neutral score for the characteristics "authentic and challenging learning tasks" $(M=.70, \mathrm{SEM}=.01, d=.66)$, "self-regulated learning" ( $M=.71, \mathrm{SEM}=.01, d=.55)$, "collaborative problem solving" $(M=.70$, $\mathrm{SEM}=.01, d=.62)$, "assessment for learning" $(M=.64, \mathrm{SEM}=.01, d=.48)$ and "structure and trust" $(M=.73, \mathrm{SEM}=.01, d=.61)$. The preference score referring to "differentiation" was less explicit $(M=.53, \mathrm{SEM}=.01)$, but still significantly higher than 0.50 , with a small effect size $(d=.12)$. The preference scores for "reflective dialogue with teachers" $(M=.45, \mathrm{SEM}=.02$, $d=0.14)$ and "reflective dialogue with peers" $(M=.38, \mathrm{SEM}=.00, d=1.00)$ were significantly lower than the neutral score. "Reflective dialogue with teachers" and "reflective dialogue with peers" were thus not preferred characteristics of PLEs in vocational education.

Table 3. Mean and Standard Error of Mean of the IPoLEVE Scales, Separately for Perception and Preference Scales, and the Extent (significance and effect) to which the Scores Differ from the Neutral Score of .50 .

\begin{tabular}{|c|c|c|c|c|c|c|c|c|}
\hline \multirow[b]{2}{*}{ Scales } & \multicolumn{4}{|c|}{ Perception } & \multicolumn{4}{|c|}{ Preference } \\
\hline & M & SEM & $p$ & $d$ & M & SEM & $p$ & $d$ \\
\hline Authentic and challenging & .59 & .04 & $.03^{*}$ & .09 & .70 & .01 & $<.001^{* * *}$ & .66 \\
\hline Self-regulated learning & .61 & .04 & $.01^{*}$ & .11 & .71 & .01 & $<.001^{* * *}$ & .55 \\
\hline Collaborative problem-solving & .62 & .03 & $<.001^{* * *}$ & .16 & .70 & .01 & $<.001^{* * *}$ & .62 \\
\hline Evaluation for learning & .54 & .04 & .40 & .04 & .64 & .01 & $<.001^{* * *}$ & .48 \\
\hline Differentiation & .44 & .04 & .09 & .07 & .53 & .01 & $<.01^{* *}$ & .12 \\
\hline Structure and trust & .59 & .06 & .10 & .07 & .73 & .01 & $<.001^{* * *}$ & .61 \\
\hline Reflective dialogue teachers & .35 & .04 & $<.001^{* * *}$ & .16 & .45 & .02 & $<.001^{* * *}$ &.-14 \\
\hline Reflective dialogue peers & .31 & .03 & $<.001^{* * *}$ & .27 & .38 & .00 & $<.001^{* * *}$ & 1.0 \\
\hline
\end{tabular}

Note: $N=532$. Neutrality $=.50$.

${ }^{*} p<.05 ;{ }^{* *} p<.01 ;{ }^{* * *} p<.001$. 
Taken together, the preferences of students in relation to their learning environment are in line with the characteristics of PLEs in vocational education, except for the setting up of reflective dialogues.

$R Q 3$ - Did student perceptions differ from their preferences with respect to the characteristics of powerful learning environments? Table 4 presents means and SEMs for the (dis) satisfaction scores, that is, the difference between student perceptions and student preferences in relation to their learning environment. Variability within these (dis)satisfaction scores is indicated by distinguishing (1) the percentage of negative scores (-) per scale, referring to the percentage of students preferring a lower visibility of the characteristics than perceived; (2) the percentage of neutral scores (=), referring to the percentage of students whose dissatisfaction scores did not differ significantly from .50 and (3) the percentage of positive scores $(+)$, referring to the percentage of students who preferred an intensification of the characteristics in their current learning environment. The rate between negative and positive scores always went in the direction of an intensification of the PoLEVE characteristics. For example, there were 3.3 times more students who preferred stronger authentic and challenging learning tasks than those who preferred less authentic and challenging learning tasks (59.7\% divided by $18.1 \%)$.

The results for each scale showed positive dissatisfaction scores, that is, students would like a stronger visibility of the PLE characteristics than they perceived in their current learning environment, in a rate from 3.3 to 6.4 times more, depending on the scale. There is a significant difference with a large effect size between student perceptions and student preferences for the scales "authentic and challenging", "self-regulated learning", "evaluation for learning", "differentiation", "structure and trust" and "reflective dialogue with teachers" $(\Delta M$ between 0.10 and $0.16, \mathrm{SEM}=.01, d>.50$ ). The differences between perceptions and preferences for the scales "collaborative problem solving" $(\Delta M=.08, \mathrm{SEM}=.01, d=.36)$ and "reflective dialogue with peers" were also significant, but showed a medium effect size $(\Delta M=.08, \mathrm{SEM}<.01, d=.32)$. We also found negative dissatisfaction scores. Between 9.7 and $18.1 \%$ of the students indicated they preferred less visibility of the characteristic, depending on the scale (see Table 4, fifth column).

$R Q 4$ - Were students who perceived their learning environment as more powerful (the "high" group), more satisfied with their learning environment than students who perceived their learning environment as less powerful (the "low" group)? Table 5 shows the results of the $K$-means clustering that grouped students according to their perceptions of the current

Table 4. Dissatisfaction scores between perceptions and preferences of the learning environment with variability (dis)satisfaction.

\begin{tabular}{|c|c|c|c|c|c|c|c|c|}
\hline Scales & $\Delta M$ & SEM & $p$ & $d$ & - & $=$ & + & Rate \\
\hline Authentic and challenging & .12 & .01 & $<.001^{* * *}$ & .51 & 18.1 & 22.2 & 59.7 & 3.3 \\
\hline Self-regulated learning & .12 & .01 & $<.001^{* * *}$ & .54 & 10.2 & 24.8 & 65.0 & 6.4 \\
\hline Collaborative-problem solving & .08 & .01 & $<.001^{* * *}$ & .36 & 16.7 & 28.8 & 54.5 & 3.3 \\
\hline Evaluation for learning & .12 & .01 & $<.001^{* * *}$ & .53 & 10.1 & 28.0 & 61.9 & 6.1 \\
\hline Differentiation & .10 & .01 & $<.001^{* * *}$ & .53 & 12.3 & 25.9 & 61.8 & 5.0 \\
\hline Structure and trust & .16 & .01 & $<.001^{* * *}$ & .53 & 10.2 & 24.2 & 65.6 & 6.4 \\
\hline Reflective dialogue teachers & .14 & .01 & $<.001^{* * *}$ & .47 & 12.2 & 38.5 & 49.3 & 4.0 \\
\hline Reflective dialogue peers & .08 & .00 & $<.001^{* * *}$ & .32 & 9.7 & 51.9 & 38.4 & 4.0 \\
\hline
\end{tabular}

Note: $N=532$. Negative score (-) within scales refers to \% students preferring less than perceived; positive score (+) refers to $\%$ students preferring more than perceived in their current learning environment. Neutral $(=)$ incorporates the \% students who's dissatisfaction scores that did not differ significantly from neutrality (.50). Rate between positive and negative scores. 
learning environment. The smallest cluster was the low group $(n=104)$, the largest cluster was the mid group $(n=243)$. The cluster of students who perceived their learning environment as highly powerful contained 186 students.

Figure 2 shows student dissatisfaction with their current learning environment as expressed by mean differences between perceived and preferred characteristics of PLEs. Differences between perceived and preferred learning environments were the highest representing the highest dissatisfaction - for students who perceived their current learning

Table 5. Group means and standard error of the mean of clusters low, medium and high perceptions with their current learning environment.

\begin{tabular}{|c|c|c|c|c|c|c|}
\hline \multirow[b]{2}{*}{ Scale } & \multicolumn{2}{|c|}{ Cluster 1 (low) $n=104$} & \multicolumn{2}{|c|}{ Cluster 2 (medium) $n=243$} & \multicolumn{2}{|c|}{ Cluster 3 (high) $n=186$} \\
\hline & $M$ & SEM & $M$ & SEM & $M$ & SEM \\
\hline Challenging and authentic & .39 & .02 & .55 & .01 & .73 & .01 \\
\hline Self-regulation & .39 & .02 & .57 & .01 & .73 & .01 \\
\hline $\begin{array}{l}\text { Collaborative } \\
\text { problem-solving }\end{array}$ & .33 & .02 & .60 & .01 & .78 & .01 \\
\hline Evaluation for learning & .29 & .01 & .50 & .01 & .69 & .01 \\
\hline Differentiation & .26 & .01 & .41 & .01 & .55 & .01 \\
\hline Structure and trust & .28 & .02 & .59 & .01 & .78 & .01 \\
\hline $\begin{array}{l}\text { Reflective dialogue } \\
\text { teachers }\end{array}$ & .17 & .03 & .31 & .02 & .46 & .02 \\
\hline Reflective dialogue peers & .07 & .04 & .27 & .02 & .42 & .02 \\
\hline
\end{tabular}

\subsection{5}

$$
0.4
$$

\subsection{5}
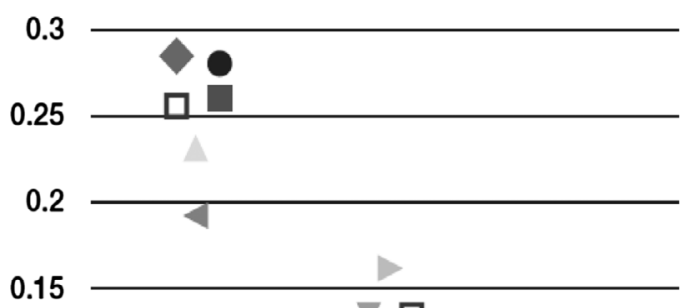

0.1
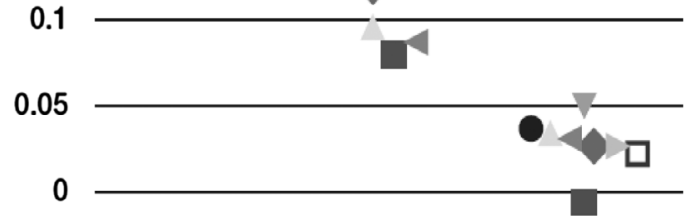

$-0.05$

\section{Authentic and Challenging}

\section{Self-regulation}

Collaborative

Problemsolving

Evaluation for Learning

\section{Differentiation}

Trust and Structure

Reflective Dialogue

Teachers

Reflective Dialogue

Peers

\section{Low perceived Medium perceived High perceived}

Figure 2. Student dissatisfaction with their current learning environment, expressed by mean differences between perceived and preferred characteristics of PLEs, according to K-means clustering of student perceptions. 
environment as the least powerful (the "low" group). On the contrary, the dissatisfaction was relatively small for the students from the medium and the high group, who perceived the characteristics of a PLE as mostly present in their current classes.

In sum, students with the lowest perceptions of their learning environment reported greater dissatisfaction. In contrast, students from the medium and the high group regarding their perceptions were more satisfied with the learning environment.

$R Q 5$ - Are students who perceived their current learning environment as highly powerful more emotionally and autonomous engaged than students who experienced their learning environment as medium or low powerful? Students who reported "disliking school" made up $24.53 \%$ of the low group and $25.36 \%$ of the high group. In contrast, students who liked to go to school, belonged for only $14.97 \%$ to the low group: $42.07 \%$ of these students experienced their learning environment as highly powerful. There was a significant difference in emotional engagement between the clusters of students who reported low, medium or high perceptions, $X^{2}(2)=18.55, p=.01$.

For cognitive engagement, we found a significant association between controlled motivation vs. autonomous motivation and the clustering of students who perceived their learning environment as low, medium or highly powerful, $X^{2}(2)=10.76, p=.005$. Students who were more motivated for the lessons out of controlled reasons constituted $23.56 \%$ of the low group and $28.38 \%$ of the high group. In contrast, only $17.81 \%$ of the students who indicated they were more motivated for autonomous reasons were grouped in the low cluster, while $36.66 \%$ of these students perceived their current learning environment as highly powerful (the "high" group).

In sum, students who perceived their current learning environment as highly powerful indicated that they were more emotionally and autonomously engaged than students who experienced their learning environment as less powerful.

\section{Discussion}

With this study, we have sought insights in student perceptions and preferences of learning environments in vocational education and student satisfaction with their learning environment. We investigated whether students who experienced characteristics of PLEs to be present in their lessons in vocational education were more satisfied with their environment and whether they were more engaged for learning. In this way, research on students' (dis) engagement turns away from a primary focus on the individual characteristics of the student and gives a more prominent place to the perceived learning environment.

First, we investigated whether students in vocational education perceived their current learning environment as a powerful one. We found evidence that student perceptions of their current learning environment were only fairly in line with the characteristics described in the PoLEVE model. Students experienced authentic and challenging learning tasks, self-regulated learning and collaborative problem-solving as characteristics that were present in the learning environment. Setting up a reflective dialogue with teachers and with peers was not perceived as present in their current learning environment, although - in contrast - literature on successful schools in supporting the growth of disadvantaged students suggests these are more likely to be using metacognitive learning strategies, such as setting up a reflective dialogue, than less effective schools (Macleod et al. 2015). 
Second, we examined what students preferred learning environment would look like. Students preferred most of the characteristics of the PoLEVE model and would like to experience these more pronouncedly than they currently perceive them in their learning environment. In particular, their preferences underline Shernoff (2014) conclusion that the most distinctive characteristic of a good learning environments is complexity, combining challenging learning tasks with support and guidance. Students themselves were asking for more challenging learning pathways. They preferred to solve more authentic problems with each other's support. This could be interpreted as a request for high expectations of teachers towards their students (Kannapel and Clements 2005). Rumberger and Palardy (2005) have shown that schools where teachers have high expectations show lower dropout rates; in contrast, lower expectations of teachers give rise to more oppositional behaviour (Demanet and Van Houtte 2012).

This demand for challenging learning pathways by students themselves went hand in hand with the need for adaptive learning support: Students clearly expressed their preference for evaluation for learning and coaching that offers structure and trust. However, the desirability of differentiation that also aims to give adaptive support was less explicit. This finding is in line with previous research findings (Könings, Brand-Gruwel, and Elen 2012). Also in a recent qualitative study (Placklé et al. 2013; Placklé et al. 2014) we found that students were struggling with the "fairness" of differentiation and their attitudes towards differentiation were ambiguous. Building a classroom environment where differences are common and open for discussion could improve the students' perception of differentiation as well (Placklé et al. 2013; Placklé et al. 2014).

Remarkably, setting up a reflective dialogue with teachers or peers was not a preferred characteristic, although it is a key element of coaching. Setting up high-quality student guidance, through a reflective dialogue between teachers and students, requires teacher competences in talking with their students instead of talking to them (Winters 2012). Teachers are struggling to set up dialogical reflective conversations (Winters et al. 2013). Because many students do not yet have positive experiences with well-designed reflective conversations (Winters 2012), they might not appreciate this particular characteristic at this moment.

Student preferences were mostly in line with the PoLEVE model but, as mentioned above, differentiation was less explicit and setting up a reflective dialogue with teachers or peers was not clearly appreciated. However, in order to meet the needs of all students, the curriculum must be adapted to their backgrounds, strengths and interests (Tomlinson and Germundson 2007; De Bruijn and Leeman 2011). The challenge in this will be to implement adaptive teaching in such a way that students perceive the value of it.

Third, we explored whether students were (dis)satisfied and found that students strongly preferred more self-regulated learning, more challenging and attractive learning tasks and more collaborative problem-solving in their learning environments. Furthermore, students preferred to have more adaptive educational support - differentiation, evaluation for learning and coaching - than they perceived they were getting at the moment.

Fourth, we were interested in whether students who perceived a PLE also reported being more satisfied with their education. Those students who experienced their environment as highly powerful were also the most satisfied, whereas students who experienced their environment as less powerful showed the lowest satisfaction. 
Finally, we examined the relation between student experiences and their levels and quality of engagement. Students who experienced the characteristics of PLEs as highly present in their education reported more emotional and autonomous engagement. This is in line with previous research on the importance of the learning environment for student satisfaction and engagement (Fullarton 2002; Willms 2003; Murray et al. 2004; Könings et al. 2011a). These findings underline the need for high quality teaching and learning in order to create more PLEs in vocational education. This requires high expectations towards teacher teams and a high degree of professionalism. Learning within authentic learning environments incorporates a shared responsibility with the local community, where strong school-community partnerships could raise engagement and learning (Zyngier 2012). A shared concern for student learning creates mutual relationships between the different actors in the learning process. These collaborations and partnerships in learning could empower teacher educators, teachers and students, which ultimately has a positive impact on teaching and learning practices.

A limitation of the current study is its correlational nature. Students who perceived the characteristics of PLEs as less present in their learning environment reported lower engagement for school, and vice versa. Students could be disengaged because they are not sufficiently challenged by the learning environment. But it remains undefined when these students lost their engagement for learning. Previous experiences could influence students' engagement and their perception of the current learning environment as well. In response to disengaged students, teachers have a tendency to lower their expectations (Yazzie-Mintz 2007) or might teach in a way that is not in line with creating PLEs, like avoiding self-regulated learning and collaborative problem-solving, resulting in a vicious cycle. Experimental investigations are needed to further clarify these relations and the causality between these variables.

Another limitation is the generalisability of the findings. The context of this study was the course PGS that integrates the different academic disciplines in vocational education in Flanders. Although we had a good sample size, we have to be careful to generalise the findings towards vocational education in general that also includes practical subjects, different streams and internships. The integrated approach of PGS, starting from real life problems and phenomena, aims that students in vocational education are not only prepared to enter their professional and personal lives with the skills of their craft and the best possible literacy, but also that they can carry on in environments which require them to make choices, to acquire, assimilate and use new information, to collaborate with others, to solve daily problems and in doing so, to regulate their strategies, their emotions and motivation. These aims of PGS, by consequence, require teachers to design their lessons in line with characteristics of the PoLEVE-model. We can argue that in other educational settings in vocational education and especially for subjects that are taught in separate lessons (not integrated) the results of student dissatisfaction with their learning environment and student engagement for learning will be even worse.

Society asks the educational system to get more inclusive. More students with special educational needs should be given a place in mainstream schooling. Additionally, more students in vocational education are expected to succeed in vocational education and leave school with a qualification. The results of our study students' perspective of characteristics of PLEs are of interest for inclusive educational settings in general (European Agency for 
Special Needs and Inclusive Education 2013). Adaptive learning support is crucial in coping with the individual differences within a classroom in a way that every learner can learn in his or her best way. This retains the inclusive approach and prevents drop-out.

To conclude, every student has the right to succeed in education. In order to ensure that students receive the education they deserve, teachers have a moral responsibility to challenge every student and to provide coaching in such a way that students are taught according to their individual strengths and needs and can reach their educational goals. Student perceptions of their current learning environment were shown to be fairly in line with the characteristics of PLEs in vocational education. In general, students in vocational education preferred a higher visibility of the characteristics of PLEs, and indicated to be dissatisfied with their current learning environments. Students strongly asked for challenging learning pathways, in combination with learning support and guidance. Moreover, students with positive perceptions of their current learning environment were also more satisfied and were stronger emotionally and autonomous engaged, which is likely to contribute to a higher learning outcomes and lower drop-out rates. These findings highlight the need to redesign curricula in vocational education and bring them more in line with the characteristics of PLEs.

\section{Disclosure statement}

No potential conflict of interest was reported by the authors.

\section{Notes on contributors}

Inge Placklé is a teacher educator at Vrije Universiteit Brussel and PXL-University College in Belgium. She educates aspirant teachers for general subjects in vocational secondary education. She is the head of the Flemish Association for Teacher Educators. Her research areas are equal learning opportunities, learning environments in vocational education and professional development of teacher educators.

Karen D Könings is an associate professor in the Department of Educational Development and Research, Faculty of Health, Medicine \& Life Sciences at Maastricht University, the Netherlands. Her research focuses on student and teacher perspectives on education, and participatory design as an approach to account for different perspectives of stakeholders in the educational design process.

Wolfgang Jacquet is an applied mathematician and professor of statistics at the Vrije Universiteit Brussel, Faculty of Psychology and Educational Sciences. His major scientific interest is the application of statistics and the development of measurements systems both from a practical and a theoretical point of view. As such he is involved in education and sustainable development.

Arno Libotton is an Emeritus Professor in Educational Sciences and Teacher Education at Vrije Universiteit Brussel. He is promotor and/or coordinator of research and development projects at university, national and EU level. He is promotor of several PhD dissertations in general and teacher education-related topics.

Jeroen J van Merriënboer is holding a chair in Learning and Instruction. He is research program director of the Graduate School of Health Professions Education at Maastricht University.

Nadine Engels is head of the Teacher Education Department at Vrije Universiteit Brussel. Her interests and expertise are mainly teacher learning and teacher development across the professional lifespan, collaborative teacher research and issues of diversity and equity. 


\section{References}

Alfassi. 2004. “Effects of a Learner-Centred Environment on the Academic Competence and Motivation of Students at Risk." Learning Environments Research 7 (1): 1-22.

Anderman, L. H., and T. M. Freeman. 2004. "Students' Sense of Belonging in School." In Advances in Motivation and Achievement. Motivating Students, Improving Schools: The Legacy of Carol Midgley, edited by M. Maehr and P. Pintrich, 27-63. Oxford: Elsevier.

Belmont, M., E. Skinner, J. Wellborn, and J. Connell. 1988. Teacher as Social Context: A Measure of Student Perceptions of Teacher Provision of Involvement, Structure, and Autonomy Support (Tech. Rep. No. 102). Rochester, NY: University of Rochester.

Boekaerts, M., and M. Niemivirta. 2000. “Self-Regulated Learning: Finding a Balance Between Learning Goals and Ego-protective Goals." In Handbook of Self-Regulation, edited by M. Boekaerts, P. R. Pintrich and M. Zeidner, 417-450. London: Academic Press.

Brown, G. T. L. 2004. "Teachers' Conceptions of Assessment: Implications for Policy and Professional Development." Assessment in Education: Principles, Policy \& Practice 11 (3): 301-318.

Brown, G. T. L. 2008. Students' Conceptions of Assessment (SCoA) Inventory (Unpublished test). Auckland, NZ: University of Auckland.

Brown, G. T. L., and L. R. Harris. 2014. "The Future of Self-assessment in Classroom Practice: Reframing Self-assessment as a Core Competency." Frontline Learning Research 2 (1): 22-30. doi: 10.14786/flr.v2i1.2.

Cleary, T. J., and B. J. Zimmerman. 2004. "Self-regulation Empowerment Program: A School-based Program to Enhance Self-regulated and Self-motivated Cycles of Student Learning." Psychology in the Schools 41 (5): 537-550.

Cohen, E. G. 1994. "Restructuring the Classroom: Conditions for Productive Small Groups." Review of Educational Research 64 (1): 1-35.

De Bruijn, E., Y. Leeman, and M. Overmaat. 2006. "Authentiek en zelfgestuurd leren in het mbo." Pedagogiek 26 (1): 45-63.

De Bruijn, E., and Y. Leeman. 2011. "Authentic and Self-directed Learning in Vocational Education: Challenges to Vocational Educators." Teaching and Teacher Education 27 (4): 694-702.

De Corte, E. 1990. "Towards Powerful Learning Environments for the Acquisition of Problem Solving Skills." European Journal of Psychology of Education 5 (1): 5-19.

De Corte, E. 2003. "Designing Learning Environments that Foster the Productive Use of Acquired Knowledge and Skills." In Powerful Learning Environments: Unravelling Basic Components and Dimensions, edited by E. De Corte, L. Verschaffel, N. Entwistle and J. J. G. van Merriënboer, 21-33. Oxford: Elsevier Science.

Deci, E. L., and R. M. Ryan, eds. 2002. Handbook of Self-Determination Research. New York: University of Rochester Press.

Demanet, J., and M. Van Houtte. 2012. “Teachers' Attitudes and Students' Opposition. School Misconduct as a Reaction to Teachers' Diminished Effort and Affect." Teaching and Teacher Education 28: 860-869.

European Agency for Special Needs and Inclusive Education. 2013. "Vocational Education and Training: Policy and Practice in the Field of Special Needs." Education. https://www.european-agency.org/sites/ default/files/agency-projects/vocational-education-and-training/20KeyFactors14-EN.pdf.

Finn, J. D., G. M. Pannozzo, and K. E. Voelkl. 1995. “Disruptive and Inattentive-Withdrawn Behavior and Achievement among Fourth Graders." The Elementary School Journal 95: 421-434.

Fredricks, J. A., P. C. Blumenfeld, and A. H. Paris. 2004. "School Engagement: Potential of the Concept, State of the Evidence." Review of Educational Research 74: 59-109.

Fullarton, S. 2002. Student Engagement with School: Individual and School-level Influences. Longitudinal Surveys of Australian Youth Research Report. Accessed 25 October 2014. http://research.acer.edu. au/lsay_research/31

Hargreaves, D. H. 2004. Learning for Life: The Foundations for Lifelong Learning. Bristol: Policy Press.

Harris, L. R., and G. T. L. Brown. 2013. "Opportunities and Obstacles to Consider When Using Peer- and Self-assessment to Improve Student Learning: Case Studies into Teachers'Implementation." Teaching and Teacher Education 36: 101-111.

Hartigan, J. A., and M. A. Wong. 1979. "Algorithm AS 136: A K-Means Clustering Algorithm." Journal of the Royal Statistical Society. Series C (Applied Statistics) 28 (1): 100-108. 
Hattie, J. 2009. Visible Learning: A Synthesis of Over 800 Meta-Analyses Relating to Achievement. London: Routledge.

Jang, H., J. Reeve, and E. L. Deci. 2010. "Engaging Students in Learning Activities: It is Not Autonomy Support or Structure but Autonomy Support and Structure." Journal of Educational Psychology 102: $588-600$.

Jennings, P. A., and M. T. Greenberg. 2009. "The Prosocial Classroom: Teacher Social and Emotional Competence in Relation to Student and Classroom Outcomes." Review of Educational Research 79: 491-525.

Johnson, D. W., and F. Johnson. 2009. Joining Together: Group Theory and Group Skills. 10th ed. Boston, MA: Allyn \& Bacon.

Kannapel, P. J., and S. K. Clements. 2005. Inside the Black Box of High Performing High-poverty Schools. Lexington, KY: The Prichard Committee for Academic Excellence.

Kicken,W.,S.Brand-Gruwel,J.J.G.vanMerriënboer,andW.Slot.2009.“DesignandEvaluationofaDevelopment Portfolio: How to Improve Students' Self-directed Learning Skills." Instructional Science 37:453-473. doi: 10.1007/s11251-008-9058-5.

Kirschner, P. A., J. Sweller, and R. E. Clark. 2006. “Why Minimal Guidance During Instruction Does Not Work: An Analysis of the Failure of Constructivist, Discovery, Problem-Based, Experiential, and Inquiry-Based Teaching." Educational Psychologist 41: 75-86.

Klem, A. M., and J. P. Connell. 2004. "Relationships Matter: Linking Teacher Support to Student Engagement and Achievement." Journal of School Health 74: 262-273. doi:10.1111/j.1746-1561.2004. tb08283.x.

Könings, K. D., S. Brand-Gruwel, and J. J. G. van Merriënboer. 2010. "An approach to participatory instructional design in secondary education:an exploratory study." Educational Research. 52: 45-59.

Könings, K. D., S. Brand-Gruwel, and J. Elen. 2012. "Effects of a School Reform on Longitudinal Stability of Students' Preferences with Regard to Education." British Journal of Educational Psychology 82: $512-532$.

Könings, K. D., S. Brand-Gruwel, and J. J. G. Merriënboer. 2005. "Towards More Powerful Learning Environments Through Combining the Perspectives of Designers, Teachers and Students." British Journal of Educational Psychology 75 (4): 645-660.

Könings, K. D., S. Brand-Gruwel, and J. J. G. van Merriënboer. 2011a. "The Match Between Students' Lesson Perceptions and Preferences: Relations with Student Characteristics and the Importance of Motivation." Educational Research 53: 439-457.

Könings, K. D., S. Brand-Gruwel, and J. J. G. van Merriënboer. 2011 b. “Participatory Instructional Redesign by Students and Teachers in Secondary Education: Effects on Perceptions of Instruction." Instructional Science 39: 737-762.

Könings, K. D., T. Seidel, and J. J. G. van Merriënboer. 2014. “Participatory Design of Learning Environments: Integrating Perspectives of Students, Teachers, and Designers." Instructional Science 42 (1): 1-9.

La Paro, K. M., and R. Pianta. 2003. CLASS: Classroom Assessment Scoring System. Charlottesville: University of Virginia.

Lamb, S., E. Markussen, R. Teese, N. Sandberg, and J. Polesel, eds. 2011. School Dropout and Completion. International Comparative Studies in Theory and Policy. Dordrecht/New York: Springer.

Little, R. J., and D. B. Rubin. 2002. Statistical Analysis with Missing Data. 2nd ed. New York: Wile.

Macleod, S., C. Sharp, D. Bernardinelli, A. Skipp, and S. Higgins. 2015. Supporting the Attainment of Disadventaged Pupils: Articulating Success and Good Practice. London: DfE.

McCormick, A. C., J. Kinzie, and R. M. Gonyea. 2013. "Student Engagement: Bridging Research and Practice to Improve the Quality of Undergraduate Education." In Higher Education: Handbook of Theory and Research. 28 vols, edited by M. B. Paulsen, 47-92. Dordrecht: Springer.

Murray, S., J. Mitchell, T. Gale, J. Edwards, and D. Zyngier. 2004. Student Disengagement from Primary Schooling: A Review of Research and Practice. A Report to the CASS Foundation. Melbourne: Monash University.

Nelson, L. M. 1999. “Collaborative Problem Solving." In Instructional Design Theories and Models: A New Paradigm of Instructional Theory, edited by C. M. Reigeluth, 241-267. Mahwah, NJ: Lawrence Erlbaum Associates Inc. 
Opdenakker, M. C., and J. Van Damme. 2009. Chapitre 3. L'efficacité des classes dans l'enseignement secondaire. In L'efficacité dans l'enseignement: Promesses et zones d'ombre, edited by V. Dupriez and X. Dumay, 55-72. Anvers: De Boeck.

Peugh, J. L., and C. K. Enders. 2004. "Missing Data in Educational Research: A Review of Reporting Practices and Suggestions for Improvement." Review of Educational Research 74 (4): 525-556.

Placklé, I., N. Engels, A. Libotton, K. Struyven, K. D. Könings, and J. J. G. van Merriënboer. 2013. "Characteristics of Powerful Learning Environments in Secondary Vocational Education as Perceived by Teacher Educators, Teachers and Students." Paper Presented at the Conference JVET, Oxford.

Placklé, I., K. D. Könings, W. Jacquet, K. Struyven, A. Libotton, J. J. G. van Merriënboer, and N. Engels. 2014. "Students' Preferred Characteristics of Learning Environments in Vocational Secondary Education." International Journal for Research in Vocational Education and Training 1 (2): 107-124.

Richards, R. W., and L. M. Richards. 2013. "Sponges Do Not Make Their Own Water: Student Engagement Through Dialogue and the Development of Reflective Consciousness." Reflective Practice 14 (6): 774-786.

Rubin, B. 2006. "Tracking and Detracking: Debates, Evidence, and Best Practices for a Heterogeneous World." Theory Into Practice 45 (1): 4-14.

Rumberger, R. 2012. Dropping Out. Why Students Drop Out of High School and What Can be Done About It. Cambridge, MA: Harvard University Press.

Rumberger, R. W., and G. J. Palardy. 2005. "Does Segregation Still Matter? The Impact of Student Composition on Academic Achievement in High School." Teachers College Record 107: 1999-2045.

Sears, D. A., and J. M. Reagin. 2013. "Individual Versus Collaborative Problem Solving: Divergent Outcomes Depending on Task Complexity." Instructional Science 41 (6): 1153-1172.

Shernoff, D. J. (2010). The Experience of Student Engagement in High School Classrooms: Influences and Effects on Long-term Outcomes. Saarbruken: Lambert Academic.

Shernoff, D. J. 2014. Optimal Learning Environments to Promote Student Engagement. Advancing Responsible Adolescent Development. New York: Springer. doi:10.1007/978-1-4614-7089-2.

Skinner, E. A., and M. J. Belmont. 1993. "Motivation in the classroom: Reciprocal effects of teacher behavior and student engagement across the school year." Journal of Educational Psychology 85: 571-581.

Skinner, E., C. Furrer, G. Marchand, and T. Kindermann. 2008. “Engagement and Disaffection in the Classroom: Part of a Larger Motivational Dynamic?" Journal of Educational Psychology 100 (4): $765-$ 781.

Smyth, J., and L. Fasoli. 2007. "Climbing Over the Rocks in the Road to Student Engagement and Learning in a Challenging High School in Australia." Educational Research 49 (3): 273-295. doi: 10.1080/00131880701550565.

Tomlinson, C. A. 1999. The Differentiated Classroom Responding to the Needs of all Learners. Alexandria, VA: Association for Supervision and Curriculum Development.

Tomlinson, C. A., and A. Germundson. 2007. "Teaching as Jazz." Educational Leadership 64 (8): 27-31.

Tomlinson, C. A., and E. L. Javius. 2012. "Teach Up for Excellence." Educational Leadership 69 (5): 28-33.

Van Landeghem, G., and J. Van Damme. 2011. Early School Leavers in Full-time Vocational Education. Starting Point for a Differentiated Approach. Leuven: Steunpunt SSL.

Van Merriënboer, J. J. G., and P. A. Kirschner. 2013. Ten Steps to Complex Learning. 2nd ed. New York: Taylor \& Francis.

Vansteenkiste, M., E. Sierens, L. Goossens, B. Soenens, F. Dochy, A. Mouratidis, N. Aelterman, L. Haerens, and Wim Beyers. 2012. "Identifying Configurations of Perceived Teacher Autonomy Support and Structure: Associations with Self-regulated Learning, Motivation and Problem Behavior." Learning and Instruction 22: 431-439. doi:10.1016/j.learninstruc.2012.04.002.

Walsh, L. and R. Black. 2009. "Overcoming the Barriers to Engagement and Equity for All Students". Paper presented at Australian Curriculum Studies Association. Biennial Conference Curriculum: a national conversation, Canberra, 2-4 October.

Willms, J. D. 2003. Student Engagement at School: A Sense of Belonging and Participation: Results from PISA 2000. Paris: Organisation for Economic Co-operation and Development.

Winters, A. (2012). "Career Learning in Vocational Education: Guiding Conversations for Career Development." Doctoral thesis., Katholieke Universiteit Leuven. Accessed 29 December 2015. https:// lirias.kuleuven.be/handle/123456789/357153 
Winters, A., F. Meijers, M. Harlaar, A. Strik, Herman Baert, and Marinka Kuijpers. 2013. “The Narrative Quality of Career Conversations in Vocational Education." Journal of Constructivist Psychology 26 (2): 115-126.

Yazzie-Mintz, E. 2007. Voices of Students on Engagement: A Report on the 2006 High School Survey of Student Engagement. Bloomington: Center for Evaluation \& Education Policy.

Zyngier, D. 2012."Raising Engagement and Enhancing Learning: School Community Partnerships that Work for Students "at Promise'".' In Breaking the Mold of Classroom Organization and Management: Innovative and Successful Practices of Engagement, Motivation, and Student Empowerment for 21st Century Schools, edited by A. Cohan and A. Honigsfeld. Rowman and Littlefield. 